\title{
IMMUNOHISTOCHEMICAL STUDY OF NUCLEAR CHANGES ASSOCIATED WITH MALE GERM CELL DEATH AND SPERMIOGENESIS
}

Leon M. McClusky ${ }^{1 *}$, Sean Patrick ${ }^{2}$, Irene E.J. Barnhoorn ${ }^{2}$, Jacobus C. van Dyk ${ }^{3}$, Christiaan de Jager ${ }^{3}$, Maria S. Bornman ${ }^{2}$

Department of Health and Nursing Science, Narvik University College, Norway ${ }^{1}$, Department of Urology ${ }^{2}$ and School of Health Systems and Public Health ${ }^{3}$, Faculty of Health Sciences, University of Pretoria, South Africa.

Running title: caspase-3 labeling of dying germ cells

Keywords: apoptosis, germ cells, nucleus, cleaved caspase-3, acrosome, GATA-4, immunohistochemistry

*Corresponding author: Leon M. McClusky, Tel +47 76966239; Fax +47 76966813 Email: leonmc@hin.no 


\begin{abstract}
In a previous study on the effects of gestational and lactational exposure of para-nonylphenol on male rats, we noted in both induced and uninduced rats, that variations in cleaved caspase3 immunostaining patterns were associated with distinct nuclear alterations in mainly basally located germ cells (spermatogonia and preleptotene spermatocytes). These were re-analysed and compared with cleaved caspase-3-labeled germ cells in the aging human and the spermatogenically active catfish testis. In the rat testes, cytoplasmic immunostaining was progressively associated with lateral compression of the nucleus, its break up into large pieces which can contain immunostained marginated chromatin masses. The pale remnants of the nucleus continued to shrink in size concomitant with the appearance of blue-purplish stained regions in the cytoplasm similar in color to the condensed chromatin in spermatids, a condition which was TUNEL-negative. These large clumps of chromatin also eventually disappeared, giving rise to cells resembling cytoplasmic ghosts, a condition which was TUNEL-positive. By contrast, the immunolabeled nuclei of human and catfish germ cells condensed into a single mass, after which they lost immunoreactivity. To exclude the possibility that these observations could reflect alterations in Sertoli nuclei, rat testicular sections were probed with a mouse anti-human GATA-4 monoclonal (MHM) antibody. The MHM was, however, the second of two GATA-4 antibodies tested, with a goat anti-mouse polyclonal (GMP) initially used to label rat the Sertoli nuclei. GMP unexpectedly, but distinctly labeled the complete development of the acrosome in the rat testis, a fortuitous finding with utility for staging of the seminiferous epithelium.
\end{abstract}




\section{INTRODUCTION}

During spermatogenesis, primitive spermatogonia enter into complex developmental pathway involving stage-related processes directed specifically towards the nuclei of their progeny prior to and after meiosis. For example, differentiating spermatogonia undergoing spontaneous physiological cell death (apoptosis) are dismantled in an orderly fashion, their chromatin compacted and/or marginated and their DNA eventually fragmented as the nuclear compartment continues to shrink (Allan et al. 1987; 1992). These deaths are considered vital for tissue homeostasis as they represent a mechanism to rid the tissue of superfluous or defective cells and has been estimated to result in a loss of $25-75 \%$ of the total number of germ cells produced in the rat testis (Huckins 1978).

Whereas the mitotic peaks of differentiating spermatogonia are associated with significant spontaneous spermatogonial death, characterized by the formation of large clumps of chromatin in these cells (Huckins 1978), the mechanism of death in other rat germ cell stages is described as complex due to the lack of classic apoptotic morphology (Russell and Clermont 1977; Allan et al. 1987; Ghosh et al. 1991, Wang et al. 1998; Bartke 1995; Russell et al. 2002). It has even been proposed that spermatocytes die via a non-apoptotic mechanism (Allan et al. 1987; 1992; Russell et al. 2002), even though the demise of these cells during the first wave of spermatogenesis in pubertal rats was subsequently found to be caspase-mediated and TUNELlabeled, in spite of the absence of pyknotic chromatin (Jahnukainen et al. 2004; Moreno et al. 2006). Since spermatogonia were also unexpectedly never labeled with the various immunofluorescent apoptotic markers used in the study of Moreno et al. (2006), these authors questioned whether spermatogonial death involved a different subtype of apoptosis, i.e. anoikis (Moreno et al. 2006). Furthermore, the identity of dying peripherally located germ cells following hormone deprivation (Billig et al. 1995) was questioned by Bartke (1995), who suggested that, based on earlier studies (Russell and Clermont 1977) on the effects of hypophysectomy in male rats, the dying germ cells were probably not spermatocytes as indicated by Billig et al. (1995), but most likely spermatogonia. Thus, our knowledge of the morphological and mechanistic aspects of male germ cell death in general is incomplete.

In the second instance, the process of spermatid differentiation, which commences after meiosis, is initiated by two major events which impact the round spermatid nucleus, i.e. the development of an acrosome from the fusion of Golgi-derived vesicles, and the shaping and maximal compaction of the chromatin in the future sperm head from a spherical configuration into its final species-specific shape (For review, Toshimori and Ito 2003; Kierszenbaum and Tres 2004). The leading edge of the expanding acrosome is a prominent marginal ring, the acroplaxome, which anchors the acrosome to the spermatid nucleus. The acroplaxome is thought to play an important role in the shaping of the spermatid head during acrosome development, such that the spermatid head changes shape from round to oblong and eventually a long thin structure, as in the case of the rat.

The commercial availability of a variety of antibodies to the host of factors constituting the apoptosome facilitates immunohistochemical detection of some of the more upstream events of apoptosis, while intracellular morphological detail is still largely retained even at the light microscopic level. Among such upstream events, is the activation of cysteine aspartylspecific proteases (caspases), of which cleaved caspase-3 is a major executioner of apoptotic morphology (Stadelmann and Lassmann 2000; Ramuz et al. 2003; Kamada et al. 2005).

In our previous report on the effects of gestational and lactational exposure of paranonylphenol $(p-\mathrm{NP})$ on male rats, variations in the immunostaining patterns obtained with a rabbit polyclonal antibody to cleaved caspase- 3 were associated with distinct nuclear alterations in mainly dying basally located germ cells in both induced and uninduced rats (McClusky et al. 2007). Since a full analysis of the range of observed apoptotic morphologies 
was outside the scope of the latter study, we now present these findings, several of which might shed further light on aspects of male germ cell death. In this qualitative and comparative study, we examined further the cleaved caspase- 3 associated intracellular changes in dying rat premeiotic germ cells, and comparisons are made with TUNEL-labeled and caspase-labeled germ cells in two other vertebrate species, the aging human and the spermatogenically active catfish. As a result of these analyses, we accidentally also found a marker of acrosome development during spermiogenesis in the rat, which may have utility in staging of the cycle of the seminiferous epithelium. 


\section{MATERIALS AND METHODS}

\section{Organisms and tissue sampling}

The present study utilized archival Bouin's fixed testicular tissues from an earlier study on the effects of para-nonylphenol ( $p$-NP) that used the modified Organization for Economic Cooperation and Development (OECD) 415 one -generation test (de Jager et al. 1999). In brief, in that study seven-day pregnant Sprague-Dawley rats received $100 \mathrm{mg} / \mathrm{kg}$, or 250 $\mathrm{mg} / \mathrm{kg} p-\mathrm{NP}$, or vehicle (cottonseed oil) only intragastrically. Dosing of all groups $(\mathrm{n}=$ 20/group) was daily, and continued through gestation, lactation, and afterwards, directly to all male offspring until 10 weeks of age. Animals were housed, according to the Animal Use and Care guidelines of the University of Pretoria, under routine laboratory conditions $(12 \mathrm{hr} / 12 \mathrm{hr}$ light-dark cycle; $22{ }^{\circ} \mathrm{C} \pm 3$ room temperature and $30-70 \%$ relative humidity) at the Laboratory Animal Facility of the Faculty of Veterinary Sciences, University of Pretoria and were given access to standard rat chow and tap water ad libitum. On the day of sampling, animals were decapitated and both testes removed. The testes were slit open after which they were immersion-fixed in Bouin's solution for 12 hours. Before further processing, testes were cut in half and fixed for a further 2.5 days before being transferred to $70 \%$ ethanol. No tissues were collected for molecular or protein analysis.

To limit the unnecessary use of animals, vehicle-treated animals served as uninduced (normal) rats in the present study, consistent with Ghosh et al. (1991) who also found no difference between sham-operated controls and normal untreated animals. For comparative analysis, testes were obtained from four men, aged 57 - 70 years old, who underwent orchidectomy as treatment for advanced prostate cancer but otherwise healthy with no known endocrine disease, as described in McClusky et al. (2007), and ten laboratory-raised sexually mature adult feral sharptooth catfish (Clarias gariepinus), sampled and processed as described in McClusky et al. (2008). These human testicular tissues were specifically used because they were the only readily available material. Fixed testes of all three species tissues were thoroughly rinsed in 70\% ethanol, before they were embedded in Tissue Tek III paraffin wax (Sakura Finetek, CA, USA).

\section{Immunohistochemistry}

Paraffin sections ( $4 \mu \mathrm{m}$ thick) from the embedded testes of all three species were floated in a water bath $\left(45^{\circ} \mathrm{C}\right)$, collected on Superfrost Plus slides (Menzel-Glaser, Germany), deparaffinized and rehydrated stepwise through an ethanol series. Deparaffinized and rehydrated sections of all three species were subjected to an antigen retrieval procedure, i.e. heating in a microwave oven $(800 \mathrm{~W})$ in $10 \mathrm{mM}$ sodium citrate buffer $(\mathrm{pH} 6.0)$ for $10 \mathrm{~min}$. After cooling for $20 \mathrm{~min}$ at RT, sections were rinsed in distilled water and treated in darkness for 10 min with $3 \%$ hydrogen peroxide to quench endogenous peroxidase. Following a rinse in distilled water, the sections were placed in $0.1 \%$ Tween 20 in phosphate buffered saline (PBS-A, $137 \mathrm{mM} \mathrm{NaCl}, 29 \mathrm{mM} \mathrm{NaH}{ }_{2} \mathrm{PO}_{4} \cdot \mathrm{H}_{2} \mathrm{O}, 9 \mathrm{mM} \mathrm{Na}_{2} \mathrm{HPO}_{4}, \mathrm{pH}$ 7.4) for $5 \mathrm{~min}$. Sections were then incubated for 1 hour at RT with a blocking solution consisting either of 5\% normal goat serum, $5 \%$ normal horse serum, or $5 \%$ normal rabbit serum in $0.1 \%$ Tween 20-PBS-A. Thereafter sections were incubated overnight at $4{ }^{\circ} \mathrm{C}$ with their respective primary antibodies, which were: a rabbit polyclonal anti-cleaved caspase-3 (17/19 kDa fragment of activated caspase-3, Cell Signaling Technology, Beverly, MA, USA) diluted 1:100, a mouse antihuman GATA-4 monoclonal antibody (sc-25310, Santa Cruz Biotechnology, Santa Cruz, CA, USA) diluted 1:200, and a goat antimouse GATA-4 polyclonal antibody (sc-1237, Santa Cruz Biotechnology, USA) diluted 1:200 in each of their respective blocking solutions. (Only the rat testicular sections were treated with the two GATA-4 antibodies). After three washes in $0.1 \%$ Tween 20/PBS-A, sections were incubated for $30 \mathrm{~min}$ at RT with either a biotinylated 
antirabbit, antimouse or antigoat IgG, washed in PBS-A, and then incubated with the Vectastain avidin-biotin-complex (Vectorlabs, Burlingame, CA, USA) for a further $30 \mathrm{~min}$ at RT. Following three 5 min PBS-A washes, the antigen was finally detected by treating the sections, according to the supplier's instructions (Vectorlabs), for 1-2 min with a 3,3'diaminobenzidine (DAB) substrate kit, after which positive immunoreactivity was revealed as brown staining. Sections were counterstained with $0.5 \%$ crystal violet-containing methyl green in $100 \mathrm{mM}$ sodium acetate (pH 4), dehydrated in 100\% butanol, cleared in xylene and mounted with Entellan permanent mounting medium (Merck, Germany). Negative controls were generated by substituting the primary antibodies with the appropriate normal serum and by serial dilution of the primary antibody.

\section{In situ end-labeling of DNA fragments (TUNEL)}

One deparaffinized and rehydrated section from all three species was pretreated with $0.5 \%$ Triton X-100 for $10 \mathrm{~min}$ at RT followed by treatment in $3 \%$ hydrogen peroxide for $7 \mathrm{~min}$ to quench endogenous peroxidise and two washes in PBS-B (50 mM sodium phosphate, $\mathrm{pH} 7.4$; $200 \mathrm{mM} \mathrm{NaCl}$ ). Subsequent steps for TUNEL staining were carried out using the ApopTagPeroxidase Kit according to the supplier's instructions (Chemicon, Temecula, CA, USA). Following incubation of the sections with the TUNEL reaction mixture in a humidified chamber at $37^{\circ} \mathrm{C}$ for $1 \mathrm{hr}$, antidigoxigenin-peroxidase complex was added for $30 \mathrm{~min}$ at RT. Sections were then treated with DAB for 1-2 min according to the supplier's instructions (Vectorlabs, Burlingame, CA) such that positive cells stained brown. Sections were counterstained with $0.5 \%$ crystal violet-containing methyl green in $100 \mathrm{mM}$ sodium acetate (pH 4.0), dehydrated in 100\% butanol, cleared in xylene and mounted with Entellan (Merck, Germany). To generate negative controls, TdT was replaced with sterile water, whereas for positive controls, sections were pretreated with DNase I (10 $\mu \mathrm{g} / \mathrm{ml}$ in distilled water) to generate DNA fragments.

\section{Microscopy and data analysis}

Cross-sections were viewed and photographed with a Nikon DXM1200F Digital camera fitted to a Nikon Optiphot microscope. As previously described in McClusky et al. (2007), because of its metachromatic staining of condensed chromatin as found during spermiogenesis, the crystal violet-containing methyl green counterstain had utility for the staging of the spermatogenic cycle in rats. Basally located cleaved caspase- 3 immunoreactive germ cells in rat testes were thus regularly observed in all rat seminiferous tubules either lacking or only with round spermatids, i.e. stages XII-XIV and I-III ( $333-426$ tubules per cross-section). All stage XII-XIV and I-III cross-sectional tubular profiles in the three rat treatment groups (n =7-10/group), at least 200 and 100 profiles in the human and catfish testicular sections were scanned, respectively. The number of caspase- and TUNEL-positive cells, as well as the type of caspase-immunoreactivity within the cells noted for each tubule. 


\section{RESULTS}

In both induced and uninduced rats, germ cells labeled with the rabbit polyclonal anticleaved caspase- 3 were found scattered around the periphery of the seminiferous epithelium (Fig. 1). Based on the stages of the seminiferous epithelium cycle in which these cells were found (McClusky et al. 2007), these were premeiotic germ cells (oblong and round shaped spermatogonia and preleptotene spermatocytes) with their readily visible low ratio of cytoplasmic volume:nuclear volume. Labeling was very distinct, and varied from discrete staining of only the cytoplasm in normal-looking cells to intense staining of the cytoplasm accompanied by changes in nuclear morphology. Although these differential immunostaining patterns clearly reflect the sequential progression of apoptosis, the intermediate stages were infrequent, which is indicative of the asynchronous nature of apoptosis in a highly heterogeneous tissue such as the seminiferous epithelium.

Nevertheless, based on the changes affecting the nucleus and its contents, all caspaselabeled rat germ cells could be grouped into several immunomorphological categories. In one group, cleaved caspase- 3 was immunolocalised to one side of the large round nucleus in the scant cytoplasm of the normal-looking germ cells (Fig. 1a). In a second group, intense cytoplasmic immunostaining was associated with what appeared to be lateral compression/deformation of the unlabeled nucleus into an oblong shape (Fig. 1a). Higher magnification of these cells revealed the unlabeled nucleus with its clear matrix to be fragmented into at least two large pieces. Another though infrequent observation of such germ cells was the intense caspase immunostaining of sharply circumscribed chromatin masses (Fig. 1b). In a third group of labeled germ cells, the pale nuclear fragments became greatly reduced size, with some cells also containing one or two large blue-purplish regions in the cytoplasm adjacent to the shrunken pale nuclear fragments (Fig. 1c). In a fourth group of cells, cleaved caspase-3 immunoreactivity was diminished, with only the blue-purplish stained regions still visible (Fig. 1d). These blue-purplish regions, which had the same color as that of the condensed chromatin in the spermatid nuclei (Fig. 1d), were small or absent in other cells with diminished cleaved caspase-3 immunoreactivity (Fig. 1e).

For comparative analyses, the aging human testis and spermatogenically active catfish testis were similarly processed and the testicular sections scanned for cleaved caspase- 3 immunoreactive germ cells. In the human testis, immunolabeled germ cells with their large ratio of cytoplasmic volume:nuclear volume, were located throughout the seminiferous epithelium, but very often along the basement membrane, indicating that these cells were mostly premeiotic germ cells, spermatocytes and occasionally round spermatids (Fig. 1f). After being initially only immunolocalised to the cytoplasm, cleaved caspase- 3 was strongly immunolocalized to the nucleus, after which immunoreactivity in human and catfish germ cell nuclei was lost and the nucleus acquired a deep blue color similar to that of the condensed chromatin in the spermatid nuclei (Fig. 1f, g). Although a different germ cell stage was immunolabeled in the catfish testis, i.e. those at secondary spermatocyte - spermatid transition, the observed variations in caspase immunostaining patterns resembled that in the human (Fig. 1g). Quantitative analysis of the main categories of caspase-labeled germ cells highlighted the chromatin differences associated with caspase immunostaining in the uninduced rat and aging human testes (Table 1).

To investigate whether these caspase-3-related nuclear changes had any relation to DNA fragmentation in situ in apoptotic germ cells, testicular sections of all three species were processed with a classic apoptotic marker which labels events downstream of cleaved caspase-3, i.e. the TUNEL assay. Since fluorescent techniques are often preferred for dual labelling studies, we opted instead for separate analysis with the TUNEL assay since overall cellular morphology with brightfield microscopy was considered of greater importance. As 
shown in Fig. 2, whereas rat germ cells containing large clumps of blue-purplish colored nuclear material were consistently not TUNEL-labeled (Fig. 2a), germ cells (spermatogonia and spermatocytes) with a rather non-descript internal morphology and diffuse nuclear content resembling ghosts and/or lacking definitive nuclear content, were often TUNELpositive (Fig. 2a,b). By comparison, cellular morphology of TUNEL-positive spermatocytes in both the human (Fig. 2c) and catfish testis (Fig. 2d) were less non-descript compared to the rat germ cells, as the outlines of their nuclei were faintly distinguishable. In the catfish testis, degenerate, shrunken cells with a single large clump of blue-purplish nuclear material were, never TUNEL-labeled (Fig. 2d), even though neighbouring germ cells could be heavily TUNEL-labeled (Fig. 2d).

One of the two types of Sertoli nuclei discovered in at least one other mammal have been found to resemble spermatogonia at the light microscopic level (McCoard et al. 2001). To exclude the possibility that these observations might involve such Sertoli nuclei which are also well-known for their irregular, lobulated shape, testicular sections of all induced and uninduced rats were probed with a protein marker for Sertoli nuclei to inform about its morphology. For this purpose, a mouse anti-human GATA-4 monoclonal antibody (MHM) was used. Fig. 3 shows that the MHM antibody distinctly labeled the basally located Sertoli nuclei in all stages of the seminiferous epithelial cycle, though the intensity of the immunolabeling varied somewhat among the stages. Weak labeling of Leydig cells were also observed in some stages (not shown). Immunostaining also revealed changes in the position of Sertoli nuclei. Whereas the nucleus was positioned with its long axis horizontally along the basement membrane in most stages (Fig. 3b), in stages III-V and VIII it tended to be positioned with its long axis perpendicular to the basement membrane (Fig. 3a). In addition, many Sertoli nuclei were also located at an intermediate position in the seminiferous epithelium in stage VIII tubules (not shown).

The immunostaining observations made with the mouse monoclonal antihuman GATA-4 (Fig. 3) were made after trial-and-error in the search for a suitable protein marker of Sertoli nuclei. The MHM antibody was actually the second of two GATA-4 antibodies tested. In our initial attempts to label the Sertoli nuclei, we used a goat anti-mouse GATA-4 polyclonal (GMP), which gave unexpected results as shown in Fig. 4 and 5 and without there being any differences in the immunostaining patterns between testes from induced and uninduced rats. Staining with the GMP antibody distinctly labeled the complete development of the acrosome, from its assembly from fused Golgi vesicles (Fig. 4a), to the lateral expansion of the acroplaxome which eventually covers almost a third of the round spermatid nucleus (Fig. 4e). This specific immunolabeling of the acrosome greatly facilitated the staging of the seminiferous epithelial cycle, from stage I through stage XIV. The GMP antibody was most intensely immunolocalised to the acrosome at the apex of particularly round spermatids, from its early stages of formation (stages I-III, Fig. 4a, b), through to all the stages during which the acroplaxome was also prominently immunostained (stages V-VIII, Fig. 4c-e) and until acroplaxome immunoreactivity began to diminish in postspermiation stages (stages IX, Fig 4f, 5a). The GMP antibody also served as a marker of nuclear elongation in the developing spermatids (stages X-XII, Fig. 5b, c) and until its completion in elongating spermatids in stage XIII tubules (Fig. 5d). In addition, the GMP distinctly labeled tubules which had undergone the second meiotic division to produce the new cohort of round spermatids (Fig. 5e). The GMP antibody did, however, label Sertoli nuclei faintly in some stages, e.g. stages IV - XII (Fig. 4f). To rule out possible batch to batch differences with commercially purchased antibodies, findings were verified with a new batch of GMP antibody kindly provided by the supplier, with identical results. 


\section{DISCUSSION}

Here we report cleaved caspase-3-associated changes in the nuclei of basally located dying male rat germ cells. These include distinct, strong cytoplasmic immunostaining associated with lateral compression or deformation of the nucleus, and its break up into large pieces which may contain marginated caspase-positive chromatin masses. Given the similar morphological fate of the oocyte nucleus in atretic rat ovarian follicles (Devine et al. 2000; Ortiz et al. 2006), these observations in dying male rat premeiotic germ cells may yet reflect an hitherto lesser known mode of death common to germ cells which are well-known for their complex mechanisms of death (Bartke 1995; Russell et al. 2002; Wang et al. 1998). The dying spermatogonia described here refer to the same dying cells described three decades ago by Huckins (1978). These may simply have been overlooked/ignored in previous analyses because of their close similarity to the adjacent spermatocytes (Billig et al. 1995; Bartke 1995) and the focus on other germ cell stages with far higher rates of apoptosis than spermatogonia (e.g. Russell and Clermont 1977). The progressive immunostaining patterns of cleaved caspase-3 early on in normal-looking rat germ cells agree with similar findings made in other tissues, and do not indicate necrosis, which is known to be negative for cleaved caspase-3 (Tsutsumi and Kamoshida 2003; Stadelmann and Lassmann 2000).

As dismantling of the nucleus is a major focus in dying nucleated cells, it is possible that alternate morphological routes in death which are not consistent with the classic morphological criteria of apoptosis may reflect spatio-structural constraints and/or stagerelated differences in various cell types. For example, differences exist in the morphological routes taken between cells with a high versus low ratio of cytoplasmic volume:nuclear volume (Suciu 1983). It is worth noting that immature rat spermatogonia with their oblong nuclei, have a low ratio of cytoplasmic volume:nuclear volume (Russell et al. 1990; De Rooij and Russell 2000) compared to human and primate germ cells with their round nuclei (Nistal et al. 1987; Johnson et al. 2001; Marshall et al. 2005). Lastly, size differences between early-stage and late-stage spermatogonia in the shark testis are also reflected in the way they die, which is via pyknosis of the entire nucleus in apoptotic immature spermatogonia and multinucleate cell formation among apoptotic mature spermatogonia (McClusky 2005; 2006). Furthermore, break up of nuclei during death has been reported in various metazoan cells, including in dying cells in a haemopoietic cell line (Dini et al. 1996), starving apoptotic cockroach midgut cells (Park et al. 2009), guinea pig vallate taste cells (Huang and Lu 2001), denervated skeletal muscle cells (Borisov and Carlson 2000) and caspase-3-mediated death of rat hippocampal neurons (Chen et al. 1998). One other instance of lateral deformation/ compression of the nucleus during apoptosis is known, i.e. during erythrocyte apoptosis in Xenopus larvae (Sakamoto et al. 2004).

Other findings of note in the present study include the shrinking of the initially large pale nuclear fragments and the appearance of blue-purplish stained regions in the cytoplasm of dying rat germ cells. Results indicate that protracted upstream cleaved capase- 3 events mediate these nuclear changes in the dying germ cells. Although caspase- 3 does not contain a nuclear-localising signal (Kihlmark et al. 2004), findings presented here nevertheless agree in principle with the reported nuclear localisation of caspase-3 in apoptotic Jurkat cells (Ramuz et al. 2003) and HepG2 cells (Kamada et al. 2005). Unlike with immunofluorescence-based assays, this immunoperoxidase-based assay sheds light on a possible stepwise sequence in cleaved caspase 3-associated germ cell apoptosis in male germ cells in these three species. One explanation could be that following cleaved caspase-3's accumulation in the cytoplasm, it either immunolocalizes to the entire nucleus in the human and catfish, or, as in the rat germ cell, it is associated with the break up of the nuclear compartment with subsequent formation of several clumps of chromatin to which cleaved caspase- 3 then immunolocalizes to. 
Thereafter, the nucleus or the chromatin masses lose caspase- 3 immunoreactivity and stain intensely blue-purple, a color similar to that of the condensed chromatin in spermatid nuclei, and is which proof that the chromatin in the apoptotic germ cell is indeed now condensed. All of these stages of the death process are TUNEL-negative in all three species, as has been previously reported (McClusky et al. 2007; 2008). By contrast, subsequent phases of the death process, i.e. the non-descript-looking cells lacking definitive nuclear content, are TUNELpositive. These latter phases correspond to what Huckins (1978) referred to as cytoplasmic ghosts which form as a result of the extrusion of the large chromatin masses out of the spermatogonial nucleus, a conclusion which was also made about dying neurons more than a century ago (Bataillon 1891; Collin 1906, in Clarke 1990). It is worth noting that the loss of several nuclear matrix chromatin-binding proteins in condensed chromatin in Jurkat cells, U937 and HeLa cells is followed by disruption of chromatin-nuclear matrix interactions such that only a non-chromatin nuclear structure remains at the end of apoptosis (Gerner et al., 2002). Taken together then, our TUNEL findings in all three species are therefore consistent with the notion that chromatin condensation and large scale internucleosomal DNA fragmentation are separate events, the latter occurring at the very end of apoptosis (Collins et al. 1997; Robertson et al. 2000). It is proposed then that these distinctive phases of apoptotic death underlie the discordances noted between cleaved caspase-3-labeling and TUNEL-labeling in the testis of the pubertal rat (Moreno et al. 2006) and adult fish (McClusky et al. 2008), ovarian follicles in buffalo and cattle (Feranil et al. 2005) and humans (Hurst et al. 2006). Given the protracted upstream events mediated by this key executioner of apoptotic morphology, findings presented here indicate that cleaved caspase- 3 immunohistochemistry is a superior method to detect apoptosis in situ.

An observed difference at the light microscope level between spermatocyte cell death in the rat, and that in the human and catfish is the indistinguishable outlines of the nucleus in the dying rat spermatocyte. Given the known complexities of spermatocyte death in rats (Allan et al. 1987; Ghosh et al. 1991, Bartke 1995; Russell et al. 2002) and the discordances between their caspase-3- and TUNEL-labeling (this study; Moreno et al. 2006), it might be that the timescales of the death process are different for unremarkable dying spermatocytes, a common feature in the seminiferous epithelium of hormone-deprived rodents (Russell and Clermont 1977; Sharpe et al. 1990; Sinha Hikim et al. 1997) and for the pyknotic death of spermatogonia. The diffuse chromatin in these dying rat spermatocytes are readily TUNEL-stained (Sinha Hikim et al. 1997; Sinha Hikim and Swerdloff 1999). Interestingly, however, pyknotic death induced experimentally in erythrocytes is slower than abrupt death induced in these cells (Burgoyne 1999). Taken together, the available evidence suggests that the long drawn out apoptotic death accompanied by pyknosis and chromatin compaction is more readily detected by cleaved caspase-3 immunohistochemistry than with the TUNEL method.

As the only intratubular supporting somatic cell, Sertoli cells express a variety of growth factors and proteins, including the zinc finger transcription factor GATA-4, which is often used as a marker of Sertoli nuclei (McCoard et al. 2001; Sawhney et al. 2005). In our hands, the Sertoli nuclei, and to a lesser extent the Leydig cells, in both induced and uninduced rats were distinctly labeled with the mouse anti-human GATA-4 monoclonal. Except for its faint labeling of Sertoli nuclei in particularly stages IV - XII, the goat polyclonal, however, distinctly labeled acrosome development during spermiogenesis, an observation hitherto not made in rats. Considering that polyclonal antibodies are well-known to cross-react with several epitopes and are prone to batch to batch variability, the labeling of acrosome development obtained here with the goat antimouse polyclonal antibody (Santa Cruz Biotechnology) was replicated with another batch from the supplier, with the exact same results. The only other reported incidence of acrosome labeling with the exact same antibody from this supplier is in adult cisplatin-treated mice, though neither the antibody dilution used 
nor length of incubation was specified in that study (Sawhney et al. 2005). This, together with the faint labeling of Sertoli nuclei reported in certain stages of the seminiferous epithelium in the present study, would suggest species-specific differences to antibody concentration and in immunoreactivity. Any other alternative explanation is difficult, except that these findings to a large extent resemble those of another study which also reported unexpected results and species-specific differences, i.e. the detection of different structures in different species (normal human, guinea pig, rat and mouse organs) with a battery of polyclonal anti-nitric oxide synthase obtained from several commercial suppliers, including Santa Cruz Biotechnology (Coers et al. 1998). For example, anti-human nitric oxide synthase from Transduction Laboratories identified neuronal cells in human neuronal tissues, but the antihuman nitric oxide synthase antibody from Santa Cruz Biotechnology failed to detect these same cells, even at high concentrations, but instead reacted with smooth muscle cells in the vessel wall (Coers et al. 1998). Moreover, differences in labeling with the goat anti-mouse polyclonal antibody to GATA-4 from this particular supplier (Santa Cruz Biotechnology) have been noted before. For example, whereas Sertoli nuclei in neonatal and postpubertal boars (McCoard et al. 2001) and early postnatal mouse testis (Viger et al. 1998) were distinctly labeled with the same goat polyclonal antibody from Santa Cruz Biotechnology, Sertoli nuclei in pubertal and adult mice totally lacked labeling (Viger et al. 1998) or were well-labeled (Sawhney et al. 2005) with this antibody from Santa Cruz Biotechnology, suggesting that interstrain and/or species-specific differences in immunoreactivities may exist.

It must be noted that two other incidences of germ cell labeling with the same goat polyclonal antibody from the same supplier are also known, namely labelling of fetal germ cells and spermatogonia in the human fetal testis and prepubertal boys, respectively (Ketola et al. 2000), and of germ cells in 23 day old mice (Viger et al. 1998). These findings, together with the reported GATA-4 gene expression in neonatal mouse testis-derived multipotent germline stem cells (Baba et al. 2007) support, in principle, our findings of germ cell GATA4 immunoexpression, the details of which remain to be elucidated. Though not excluding the possibility of false positive staining, this fortuitous labeling of acrosome development with the goat anti-mouse GATA-4 polyclonal provides another alternative to the use of peanut and soybean agglutinin lectin histochemistry (Malmi and Söderström 1988) in the staging of the cycle of the seminiferous epithelium in rats. Unlike the fixative- and pepsin-treatmentdependent variations in the staining patterns of these two lectins in the testis (Malmi and Söderström 1988), the method presented here is facile with fixatives and pretreatments commonly used in immunohistochemistry.

In conclusion, findings presented here show that the rabbit polyclonal anti-cleaved caspase- 3 in combination with methyl green counterstaining has utility in highlighting the differences in nuclear alterations between dying germ cells in rats, and those in human and catfish, which have a readily visible greater ratio of cytoplasmic volume:nuclear volume than rat germ cells. Additional immunohistochemical evidence is also presented which highlights the crossreactivities for which polyclonal antibodies are renowned for, but which resulted in the fortuitous labeling of acrosome development during spermiogenesis.

\section{ACKNOWLEDGMENTS}

The authors express their appreciation to the Department of Physiology, University of Pretoria for laboratory facilities, Prof. J.H.J van Vuren of the Department Zoology, University of Johannesburg for providing laboratory aquarium facilities for the rearing of the catfish, and Dr EH Abdel Goad of the Department of Urology, Nelson Mandela School of Medicine, University of KwaZulu Natal for supplying the human testicular tissues. Financial support from the National Research Foundation of South Africa (Project no's. NRF 9657, NRF 9657) 
and the Water Research Commission of South Africa (K5/1505) is acknowledged. The authors thank Mrs. Joey Breedt of the Dept. of Veterinary Pathology, Faculty of Veterinary Sciences, University of Pretoria for tissue sectioning, Mr. Alan Hall of the Laboratory for Microscopy and Microanalysis, University of Pretoria for assistance with digital photomicrography, and Dr. Ross Wakelin for his comments on the manuscript. 


\section{REFERENCES}

Allan DJ, Harmon BV, Kerr JFR (1987) Cell death in spermatogenesis. In: Potten CS (ed) Perspectives on mammalian cell death. Oxford University Press, London, pp 229-258

Allan DJ, Harmon BV, Roberts SA (1992) Spermatogonial apoptosis has three morphologically recognizable phases and shows no circadian rhythm during normal spermatogenesis in the rat. Cell Prolif 25:241-250

Baba S, Heike T, Umeda K, Iwasa T, Kaichi S, Hiraumi Y, Doi H, Yoshimoto M, KanatsuShinohara M, Shinohara T, Nakahata T (2007) Generation of cardiac and endothelial cells from neonatal mouse testis-derived multipotent germline stem cells. Stem Cells 25:1375-1383

Bartke A (1995) Editorial: Apoptosis of male germ cells, a generalized or a cell type-specific phenomenon? Endocrinology 136:3-4

Billig H, Furuta I, Rivier C, Tapanainen J, Parvinen M, Hsueh AJW (1995) Apoptosis in testis germ cells: developmental changes in gonadotropin dependence and localization to selective tubule stages. Endocrinology 136:5-12

Borisov AB, Carlson BM (2000) Cell death in denervated skeletal muscle is distinct from classical apoptosis. Anat Rec 258:305-318

Burgoyne LA (1999) The mechanisms of pyknosis: hypercondensation and death. Exp Cell Res 248:214-222

Chen J, Nagayama T, Jin K, Stetler RA, Zhu RL, Graham SH, Simon RP (1998) Induction of caspase-3-like protease may mediate delayed neuronal death in the hippocampus after transient cerebral ischemia. J Neuroscience 18:4914-4928

Clarke PGH (1990) Developmental cell death: morphological diversity and multiple mechanisms. Anat Embryol 181:195-213

Coers W, Timens W, Kempinga C, Klok PA, Moshage H (1998) Specificity of antibodies to nitric oxide synthase isoforms in human, guinea pig, rat, and mouse tissues. J Histochem Cytochem 46:1385-1391

Collins JA, Schandl CA, Young KK, Vesely J, Willingham MC (1997) Major DNA fragmentation is a late event in apoptosis. J Histochem Cytochem 45:923-934

de Jager C, Bornman MS, Van der Horst G (1999) II. The effect of p-nonylphenol on the fertility potential of male rats after gestational, lactational and direct exposure. Andrologia $31: 107-113$

De Rooij DG, Russell LD (2000) All you wanted to know about spermatogonia but were afraid to ask. J Androl 21:776-798

Del Bino G, Darzynkiewicz Z, Degraef C, Mosselmans R, Fokan D, Galand P (1999) Comparison of methods based on annexin- $\mathrm{V}$ binding, DNA content or TUNEL for evaluating cell death in HL-60 and adherent MCF-7 cells. Cell Prolif 32:25-37 
Devine PJ, Payne CM, McCuskey MK, Hoyer PB (2000) Ultrastructural evaluation of oocytes during atresia in rat ovarian follicles. Biol Reprod 63:1245-1252

Dini L, Coppola S, Ruzittu MT, Ghibelli L (1996) Multiple pathways for apoptotic nuclear fragmentation. Exp Cell Res 223:340-347

Feranil JB, Isobe N, Nakao T (2005) Apoptosis in the antral follicles of swamp buffalo and cattle ovary: TUNEL and caspase-3 histochemistry. Reprod Dom Anim 40:111-116

Gerner C, Gotzmann J, Fröhwein U, Schamberger C, Ellinger A, Sauermann G (2002) Proteome analysis of nuclear matrix proteins during apoptotic chromatin condensation. Cell Death Differ 9:671-681

Ghosh S, Sinha-Hikim AP, Russell LD (1991) Further observations of stage-specific effects seen after short-term hypophysectomy in the rat. Tiss Cell 23:613-630

Huang Y, Lu K (2001) TUNEL staining and electron microscopy studies of apoptotic changes in the guinea pig vallate taste cells after unilateral glossopharyngeal denervation. Anat Embryol 204:493-501

Huckins C (1978) The morphology and kinetics of spermatogonial degeneration in normal adult rats: an analysis using a simplied classification of the germinal epithelium. Anat Rec 190:905-926

Hurst PR, Mora JM, Fenwick MA (2006) Caspase-3, TUNEL and ultrastructural studies of small follicles in adult human ovarian biopsies. Human Reprod 21:1974-1980

Jahnukainen K, Chrysis D, Hou M, Parvinen M, Eksborg S, Soder O (2004) Increased apoptosis occurring during the first wave of spermartogenesis is stage-specific and primarily affects mid-pachytene spermatocytes in the rat testis. Biol Reprod 70:290-296

Johnson L, Staub C, Neaves WB, Yanagimachi R (2001) Live human germ cells in the context of their spermatogenic stages. Human Reprod 16:1575-1582

Kamada S, Kikkawa U, Tsjujimoto Y, Hunter T (2005) Nuclear translocation of caspase-3 is dependent on its proteolytic activation and recognition of a substrate-like protein(s). J Biol Chem 280:857-860

Ketola I, Pentikäinen V, Vaskivuo T, Ilvesmäki V, Herva R, Dunkel L, Tapanainen JS, Toppari J, Heikinheimo M (2000) Expression of transcription factor GATA-4 during human testicular development and disease. J Clin Endocrinol Metab 85:3925-3931

Kierszenbaum AL, Tres LL (2004) The acrosome-acroplaxome-manchette complex and the shaping of the spermatid head. Arch Histol Cytol 67:271-284

Kihlmark M, Rustum C, Eriksson C, Beckman M, Iverfeldt K, Hallberg E (2004) Correlation between nucleocytoplasmic transport and caspase-3-dependent dismantling of nuclear pores during apoptosis. Exp Cell Res 293:346-356 
Malmi R, Söderström KO (1988) Lectin binding to rat spermatogenic cells: effects of different fixation methods and proteolytic enzyme treatment. Histochem J 20:276-282

Marshall GR, Ramaswamy S, Plant TM (2005) Gonadotropin-independent proliferation of the pale type A spermatogonia in the adult rhesus monkey (Macaca mulatta). Biol Reprod $73: 222-229$

McClusky LM (2005) Stage and season effects on cell cycle and apoptotic activities of germ cells and Sertoli cells during spermatogenesis in the spiny dogfish (Squalus acanthias). Reproduction 129:89-102

McClusky LM (2006) Stage-dependency of apoptosis and the blood-testis barrier in the dogfish shark (Squalus acanthias): cadmium-induced changes as assessed by vital fluorescence techniques. Cell Tiss Res 325:541-553

McClusky LM, De Jager C, Bornman MS (2007) Stage-related increase in the proportion of apoptotic germ cells and altered frequencies of stages in the spermatogenic cycle following gestational, lactational and direct exposure of male rats to $p$-nonylphenol. Toxicol Sci 95: 249256

McClusky LM, Barnhoorn IEJ, Van Dyk JC, Bornman MS (2008) Testicular apoptosis in feral Clarias gariepinus using TUNEL and cleaved caspase-3 immunohistochemistry. Ecotoxicol Environ Saf 71:41-46

McCoard SA, Lunstra DD, Wise TH, Ford JJ (2001) Specific staining of Sertoli cell nuclei and evaluation of Sertoli cell number and proliferative activity in Meishan and White Composite Boars during the neonatal period. Biol Reprod 64:689-695

Moreno RD, Lizama C, Urzúa, Vergara SP, Reyes JG (2006) Caspase activation throughout the first wave of spermatogenesis in the rat. Cell Tiss Res 325:533-540

Nistal M, Codesal J, Paniagua R, Sanatmaria L (1987) Decrease in the number of human Ap and Ad spermatogonia and in the Ap/Ad ratio with advancing age. New data of the spermatogonial stem cell. J Androl 8:64-68

Ortiz R, Echeverria OM, Salgado R, Escobar ML, Vázquez-Nin GH (2006) Fine structural and cytochemical analysis of the processes of cell death of oocytes in atretic follicles in new born and prepubertal rats. Apoptosis 11:25-37

Orwig KE, Ryu B, Avarbock MR, Brinster RL (2002) Male germ-line stem cell potential is predicted by morphology of cells in neonatal rat testes. Proc Natl Acad Sci 99:11706-11711

Park MS, Park P, Takeda M (2009) Starvation induces apoptosis in the midgut nidi of Periplaneta americana: a histochemical and ultrastructural study. Cell Tiss Res 335:631-638

Ramuz O, Isnardon D, Devilard E, Charafe-Jauffret E, Hassoun J, Birg F, Xerri L (2003) Constitutive nuclear localization and initial cytoplasmic apoptotic activation of endogenous caspase-3 evidenced by confocal microscopy. Int J Exp Pathol 84:75-81 
Robertson JD, Orrenius S, Zhivotovsky B (2000) Review: nuclear events in apoptosis. J Struct Biol 129:346-358

Russell LD, Clermont Y (1977) Degeneration of germ cells in normal, hypophysectomized and hormone treated hypophysectomized rats. Anat Rec 187:347-366

Russell LD, Ettlin RA, Sinha Hikim AP, Clegg ED (1990) Histological and histopathological evaluation of the testis. Cache River Press, Clearwater, FL

Russell LD, Chiarini-Garcia H, Korsmeyer SJ, Knudson CM (2002) Bax-dependent spermatogonia apoptosis is required for testicular development and spermatogenesis. Biol Reprod 66:950-958

Sakamoto MK, Mima S, Kihara T, Tanimura T (2004) Sequential morphological changes of erythrocyte apoptosis in Xenopus larvae exposed to 2,3,7,8-tetrachlorodibenzo- $p$-dioxin (TCCD). Anat Rec 279A:652-663

Sawhney P, Giammona J, Meistrich ML, Richburg JH (2005) Cisplatin-induced long-term failure of spermatogenesis in adult C57/B1/6J mice. J Androl 26:136-145

Sharpe RM, Maddocks S, Kerr JB (1990) Cell-cell interactions in the control of spermatogenesis as studied using Leydig cell destruction and testosterone replacement. Am J Anat 188:3-20

Sinha Hikim AP, Rajavashisth TB, Sinha Hikim I, Lue Y, Bonavera JJ, Leung A, Wang C, Swerdloff RS (1997) Significance of apoptosis in the temporal and stage-specific loss of germ cells in the adult rat after gonadotropin deprivation. Biol Reprod 57:1193-1201

Sinha Hikim AP, Swerdloff RS (1999) Hormonal and genetic control of germ cell apoptosis in the testis. Reviews Reprod 4:38-47

Stadelmann C, Lassmann H (2000) Detection of apoptosis in tissue sections. Cell Tiss Res 301:19-31

Suciu D (1983) Cellular death by apoptosis in some radiosensitive and radioresistant mammalian tissues. J Theor Biol 105:391-401

Toshimori K, Ito C (2003) Formation and organization of the mammalian sperm head. Arch Histol Cytol 66:383-396

Tsutsumi Y, Kamoshida S (2003) Pitfalls and caveats in histochemically demonstrating apoptosis. Acta Histochem Cytochem 36:271-280

Viger RS, Mertineit C, Trasler JM, Nemer M (1998) Transcription factor GATA-4 is expressed in a sexually dimorphic pattern during mouse gonadal development and is a potent activator of the Müllerian inhibiting substance promoter. Development 125:2665-2675

Wang R, Nakane PK, Koji T (1998) Autonomous cell death of male germ cells during fetal and postnatal period. Biol Reprod 58:1250-1256 


\section{LEGENDS}

Figure 1. Comparative immunostaining patterns of apoptotic germ cells with the rabbit polyclonal cleaved caspase- 3 antibody in paraffin testicular sections of $p$-NP-induced and uninduced rats (a-e), aging human (f) and spermatogenically active catfish (g) testes. (Sections were counterstained with methyl green containing crystal violet). (a) A stage XIII tubule of an induced rat with several caspase-3 labeled germ cells showing sequential alterations in nuclear morphology associated with progressive cytoplasmic immunostaining, including lateral compression of the nucleus (arrowhead). Inset in (a) is a high magnification sagittal view of such germ cells which shows the nucleus to be fragmented into at least two large pale pieces, as seen in this tubule from an uninduced rat. (b) Another aspect (lateral view) of these large nuclear fragments showing cleaved caspase-3 strongly immunolocalized to two sharply circumscribed dense chromatin masses fragments, as seen in a tubule from an induced rat. In other labeled germ cells, (c) the nuclear fragments were much reduced in size (arrows), as seen in this strongly immunostained spermatogonium in an induced rat. Inset in (c) is a high magnification of a slightly earlier stage showing a blue stained region $\left(^{*}\right)$ in the cytoplasm associated with three small pale nuclear fragments (arrows), as seen in this immunostained spermatogonium from an uninduced rat. (d) With diminishing immunoreactivity, as seen in this tubule from an uninduced rat, only the blue-purplish stained regions remain readily visible, with these having the same color as the condensed chromatin in spermatid nuclei (arrow). (e) The blue-purplish-stained regions also eventually become smaller (arrow) until they are no longer observed in the still moderately immunostained cytoplasm (arrowhead), as can be seen in this tubule from an induced rat. (f) In the aging human testis, the entire germ cell, with its large ratio of cytoplasmic volume:nuclear volume, can be intensely immunostained, or only the cytoplasm with the nucleus staining blue similar in color to that of the spermatozoa head. Inset in (f) shows a germ cell with cleaved caspase-3 strongly immunolocalised to the large intact nucleus. (g) In the catfish, immunostaining varied from being strictly cytoplasmic (inset), to nuclear (arrow), and to cytoplasmic at which point the nuclei have an intense blue color similar to that of condensed chromatin in the spermatozoa heads. Psc, primary spermatocytes; Ssc, secondary spermatocytes; sz, spermatozoa. Bar: $\mathrm{a}=20 \mu \mathrm{m} ; \mathrm{b}, \mathrm{c}, \mathrm{d}, \mathrm{f}, \mathrm{g}=10 \mu \mathrm{m}$.

Figure 2. Comparative TUNEL-staining patterns of apoptotic germ cells in testicular sections of the rat (a,b), aging human (c) and spermatogenically active catfish (d) testes. (Sections were counterstained with methyl green containing crystal violet). Testicular sections from induced and uninduced rats gave similar results. (a) In the rat testis, non-descript-looking germ cells are TUNEL-labeled (arrow). Spermatogonia with several blue-purplish colored regions are TUNEL-negative $(*)$. (b) A stage XIV rat seminiferous tubule showing an out-ofposition TUNEL-labeled primary spermatocyte located among secondary spermatocytes. (c) The nuclei of TUNEL-labeled germ cells in the human testis are faintly discernible. Inset in (c) shows the rare occurrence of a TUNEL-labeled human germ cell with two large bluepurplish colored nuclear fragments. (d) In the catfish testis, primary and secondary spermatocytes are often strongly TUNEL-labeled. Note that the shrunken germ cells, whose nuclear compartments stain intense blue, are TUNEL-negative. Psc, primary spermatocytes; Ssc, secondary spermatocytes; st, spermatids; sz, spermatozoa. Bar $=10 \mu \mathrm{m}$.

Figure 3. Immunostaining of rat testicular sections with the mouse anti-human GATA-4 monoclonal antibody. Testicular sections from induced and uninduced rats gave similar results. (a) A stage III/IV tubule showing distinct labeling of the oblong shaped basally 
located Sertoli nuclei. Some of the Sertoli nuclei have their long axes perpendicular to the basement membrane. (b) A stage XII tubule showing oblong Sertoli nuclei with their long axes lying horizontally along the basement membrane. Bar $=30 \mu \mathrm{m}$.

Figure 4. Stages of the rat seminiferous epithelial cycle (Part I), based on the immunostaining patterns with the goat anti-mouse GATA-4 polyclonal antibody. Testicular sections from induced and uninduced rats gave similar results. (a) Stage I. Antibody labels the Golgi-phase of acrosome development. Note that the blue stained nuclei of the elongating spermatids are generally located adluminally to the round spermatids with their small developing acrosomes. (b) Stage III. Increased immunoreactivity indicates the enlarged acrosomal region. Note that the blue-stained nuclei of the elongating nuclei have started to penetrate the seminiferous epithelium such that they reach the primary spermatocytes. (c) Stage V. Immunostaining shows the spreading of the acrosome over the round spermatid nucleus. Many of the elongated spermatid heads are deeply embedded in the epithelium. (d) Stage VI.

Immunostaining labels the spreading acroplaxome across the spermatid nuclear surface, with the acrosome at the apex of the spermatid nucleus most intensely immunostained. Note that the nuclei of elongated spermatids have retracted towards the tubule lumen. (e) Stage VIII. The moderately immunostained acroplaxome covers about a third of the round spermatid nuclear surface. The blue-purple-stained nascent residual bodies are layered between the mature spermatid nuclei and the round spermatids. (f) Stage IX. A recently spermiated tubule, with a few remaining spermatids among the residual bodies near the tubule lumen. Labeling of the acroplaxome is somewhat reduced. Note the reorientation of the spermatid nuclei with their apices towards the basement membrane. This stage is one of the few stages in which the Sertoli nuclei are faintly immunolabeled (arrowheads). Bar $=30 \mu \mathrm{m}$.

Figure 5. Stages of the rat seminiferous epithelial cycle (Part II), based on the immunostaining patterns with the goat anti-mouse GATA-4 polyclonal antibody. Testicular sections from induced and uninduced rats gave similar results. (a) Late stage IX. Less prominently immunostained acrosomes clearly identify round spermatids as the only postmeiotic germ cells present in the epithelium at this stage of the cycle. Note that the residual bodies are absent. (b) Stage X. The spermatid nuclei have started to elongate. Immunostaining shows the acrosomic head cap to extend from the apex towards the caudal region of the V-shaped spermatid head. Some of these early elongating spermatids have started to embed themselves deep into the epithelium, but they are not bundled yet. (c) Stage XII. Moderate immunostaining along the length of elongated spermatid nuclei, which continue to embed themselves deeper into the Sertoli cell body. Early signs of bundling of the young spermatids can be observed. (d) Stage XIII. The spermatid nuclei are still immunolabeled. Condensation of the chromatin in the spermatid nuclei has been completed, as judged by their blue color reaction with the counterstain. The spermatid heads are bundled together as they penetrate the Sertoli cell bodies through to the level of the pachytene spermatocytes. (e). Early Stage I. The highly condensed nuclei of the elongated spermatids are still prominently immunolabeled. The faint specks tightly associated with the nucleus of the round spermatids are the immunolabeled Golgi vesicles which mark the assembly of the new acrosome in these newly formed round spermatids. (f) Negative control of a stage VIII tubule (left) and other stages (right), following the omission of the primary antibody. Bar $=30$ $\mu \mathrm{m}$. 


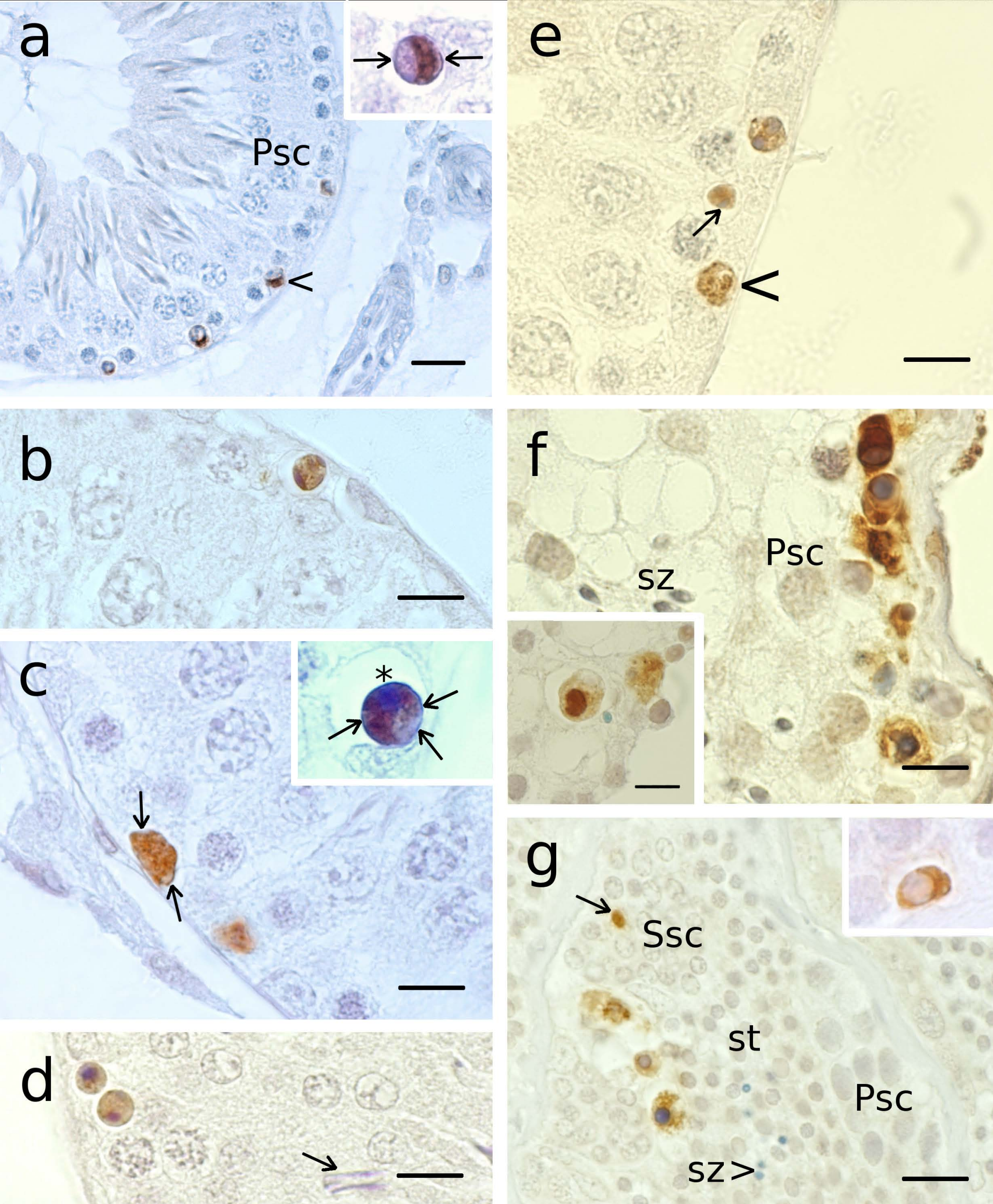




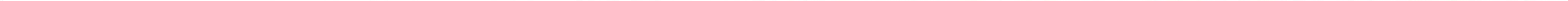




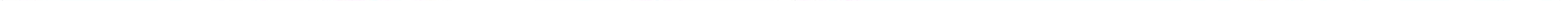


